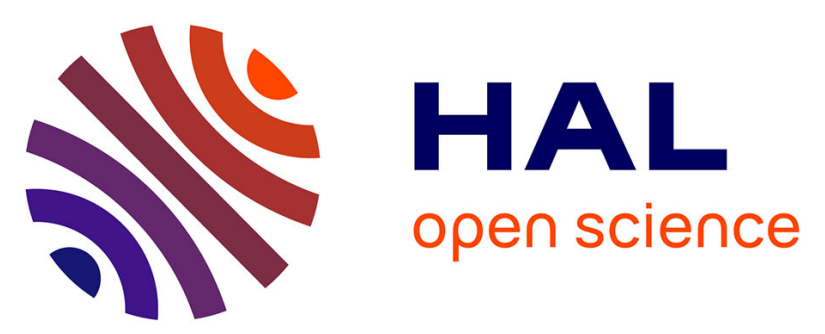

\title{
Implementation and evaluation of the population-based programme "health literacy in school-aged children" (GeKo)
}

\author{
Marco Franze, Konstanze Fendrich, Carsten Oliver Schmidt, Ruth Anja
} Fahland, Jochen René Thyrian, Sandra Plachta-Danielzik, Jasmin Seiberl, Wolfgang Hoffmann, Christian H. Splieth

\section{To cite this version:}

Marco Franze, Konstanze Fendrich, Carsten Oliver Schmidt, Ruth Anja Fahland, Jochen René Thyrian, et al.. Implementation and evaluation of the population-based programme "health literacy in school-aged children" (GeKo). Journal of Public Health, 2011, 19 (4), pp.339-347. 10.1007/s10389011-0421-7 . hal-00634005

\section{HAL Id: hal-00634005 https://hal.science/hal-00634005}

Submitted on 20 Oct 2011

HAL is a multi-disciplinary open access archive for the deposit and dissemination of scientific research documents, whether they are published or not. The documents may come from teaching and research institutions in France or abroad, or from public or private research centers.
L'archive ouverte pluridisciplinaire HAL, est destinée au dépôt et à la diffusion de documents scientifiques de niveau recherche, publiés ou non, émanant des établissements d'enseignement et de recherche français ou étrangers, des laboratoires publics ou privés. 
Franze $\mathbf{M}^{1^{*}}$, Fendrich $\mathrm{K}^{1}$, Schmidt $\mathrm{C} \mathrm{O}^{2}$, Fahland $\mathbf{R} \mathrm{A}^{2}$, Thyrian $\mathbf{J} \mathbf{R}^{1}$, Plachta-Danielzik $\mathrm{S}^{3}$, Seiberl $\mathbf{J}^{3}$, Hoffmann $W^{1}$, Splieth $C^{4}$ Implementation and evaluation of the population-based programme „Health literacy in school-aged children" $\left(\mathrm{GeKo}^{\mathrm{KidS}}\right)$

1 Institute for Community Medicine, Dept. Epidemiology of Health Care and Community Health, University of Greifswald

2 Institute for Community Medicine, Dept. Methods of Community Medicine, University of Greifswald

3 Institute for Human Nutrition and Food Studies, University of Kiel

4 Preventive and Pediatric Dentistry, University of Greifswald

* Corresponding author:

Dr. Marco Franze, Institute for Community Medicine, Dept. Epidemiology of Health Care and Community Health, University of Greifswald, Ellernholzstr. 1-2, 17487 Greifswald, marco.franze@ uni-greifswald.de 
Implementation and evaluation of the population-based programme „Health literacy in school-aged children” $\left(\right.$ GeKo $\left.^{\text {KidS }}\right)$

- Blinded manuscript - 


\section{Abstract:}

Aim: Health literacy (HL) is a key outcome of health education. Low HL is associated with a higher risk for healthrelated impairments and a high amount of health-related costs. This paper describes therefore the contents and evaluation of the school-based programme "Health literacy in school-aged children" (GeKo ${ }^{\mathrm{KidS}}$ ) and its acceptance by teachers. A second focus of the paper is the description of methods to increase response in schools, students, and parents as a crucial condition for the validity and generalizability of results from epidemiologic prevention studies.

Subjects and methods: The evaluation of the prevention program GeKo ${ }^{\mathrm{KidS}}$ included 5th grade students aged 9-13 years in schools in the region of Greifswald and East Pomerania (longitudinal randomised control group pre-postdesign (RCT)). Data collections took place within the extended school dentist examination at the beginning of school year 2007/2008 and at the beginning of the second half term of school year 2008/2009. This included medical examinations and self-completion-questionnaires of students, parents and teachers. The study was authorised by the data protection commissioner of Mecklenburg-West Pomerania, the Ministry of Education, Science and Culture of Mecklenburg-West Pomerania and the Ethics Commitee of the Ernst-Moritz-Arndt-University Greifswald. Based on the authorization of the data protection concept and concerns about selective response, parents were not granted a consent but a right to refuse participation.

In order to attain a high participation of the schools the school principals were informed about the research project by an invitation letter, telephone calls and personal visits. Additionally an agreement on participation was handed out to all schools as a binding criterion for participation. By signing this agreement schools committed to use the offered teaching material, to participate in teachers' training and evaluation and to provide resources with respect to time and space.

At the beginning of school year 2007/2008 all parents of 5th grade students were informed about the research project, the prevention programme, and aspects of data protection. In order to increase the response rate parents also received a supporting letter of the Minister of Education, Science and Culture of Mecklenburg-West Pomerania which mainly informed about the importance of the research project and asked for support of this study.

Results: In Greifswald/East Pomerania 19 of 22 schools with 5th year classes participated in GeKo ${ }^{\text {KidS }}$ (response: $86.3 \%$ ). Out of 914 eligible students in the participating schools 882 children (96.4\%) took part in the school dentist examination. 863 children (94.4\%) participated in the extended school dentist examination. 852 children (93.2\%) took part in the survey of students. In the parental survey 721 parents participated (response: 78.8\%). A high amount of acceptance referring to the teachers' training and the appropriateness of the GeKo ${ }^{\text {KidS }}$ programme can be reported. Conclusion: Referring to the low rate of refusal the programme and the evaluation study were well accepted. Possible reasons for these results could be the chosen procedure of establishing contact with schools before sending the questionnaires and the parent's right to refuse the participation of their child instead of giving an active confirmation. Due to this high response rate the data base enables comprehensive conclusions on the health-related state of students in Greifswald/East Pomerania.

Key words School-based prevention. Health Literacy, Response, GeKoKidS, Germany

\section{Background}


The main goal of the population-based project $\mathrm{GeKo}^{\mathrm{KidS}}$ is the evaluation of a programme for the promotion of health literacy in school-aged children which was developed based on the theory of Nutbeam (2000). Nutbeam defines health literacy (HL) as "personal, cognitive and social skills which determine the ability of individuals to gain access to, understand, and use information to promote and maintain good health". His model highlights HL as a key outcome of health education and consists of three distinctions, i.e. functional HL, interactive HL and critical HL. Thus, HL is more than the transmission of information or the development of skills to be able "to read pamphlets and successfully make appointments" but also includes health-related knowledge, attitudes, motivation, behavioural intentions, personal skills, and self-efficacy.

Promoting HL is necessary since low HL is associated with a higher risk of health-related impairments, e.g. a lower health-related status (Baker et al. 1997; Wolf et al. 1946-1952; von Wagner et al. 2007), higher prevalence rates of cardiovascular diseases (Gazmararian et al. 2006), diabetes (Schillinger et al. 2002), asthma (Mancuso \& Rincon 2006), obesity (Hawthorne 1997; Goodman 1999; Sharif \& Blank 2010), and a higher amount of tobacco- and alcohol consumption (Conwell et al. 2003; von Wagner et al. 2007). Low HL is also associated with a high amount of health-related costs (Robert Koch-Institut 2009a).

\section{The GeKo ${ }^{\text {KidS }}$ programme: Goals, contents and implementation}

The GeKo ${ }^{\text {KidS }}$ programme (Franze et al. 2010a) was developed as a compilation of components of already published health promotion and prevention programs for children aged 9 to 13 years. The goals of the GeKo ${ }^{\text {KidS }}$ programme are:

- $\quad$ the promotion of dental health,

- the promotion of vaccination,

- the prevention of starting smoking,

- $\quad$ the prevention of chronic pain,

- $\quad$ the prevention of obesity including an improved nutritional status, and

- $\quad$ the promotion of physical activity.

Teachers received three special trainings to implement the GeKo ${ }^{\mathrm{KidS}}$ programme in the school subjects biology, physical education and maths. The following section describes the teaching material referring to aspects of HL as well as contents of the training for teachers. During each training teachers received a booklet containing the slides of the given presentation about the theoretical and scientific/epidemiological background (e.g. on the theory of Nutbeam or on prevalence rates of caries, overweight and obesity) as well as master copies of the teaching material.

Description of the teaching material on dental health/oral prevention:

Background: Caries prevention within the $\mathrm{GeKo}^{\mathrm{KidS}}$ programme is generally based on evidence-based interventions such as 1 . fluoride use, 2. oral hygiene, 3. the reduction of sugar, especially in drinks and 4. visiting the dentist. Since prevention strategies with focus on consultations of dentists based on a walk-in-model ("Komm-Struktur”) are less sufficient for improving dental health of persons with low socio-economic status (Kay \& Locker 1998; Schiffner \& 
Bauch 1986; Splieth et al. 2005) the teaching material of GeKo ${ }^{\text {KidS }}$ emphasizes the necessity of simple-structured, exploring and more efficient interventions in schools e.g. brushing teeth and fluoride use in schools (Splieth et al. 2004; Trummler \& Weiss 2000; Zimmer et al. 1999).

Teaching material: With help of teaching material on dental health students are briefed concerning the cariogen impact of sugar- and carbohydrate-containing food. Furthermore they are informed as well that dental plaque leads to caries and what they can do against caries i.e. the improvement of fluoride use (using toothpastes with a fluoride concentration of $1250 \mathrm{pm}$ at least and a weekly use of high fluoride gels), brushing technique and brushingfrequency (two times a day).

The main goal of the teaching material on dental health is the improvement of dental HL: In order to be able to recognize the frequency of cariogenic snacks, students use a nutrition schedule to fill in all the beverage and foodimpulses (including length of time and point of time). The schedule can then be analysed by the teacher and/or the dentist. In order to receive professional help concerning caries prevention students are motivated as well to participate in biannual free of charge dentist's screening.

The teaching units on dental health are particularly suitable for the school subject biology but they can also be used in maths (the teaching material also includes working sheets for calculations of percentage on caries prevalence in one class comparing to the mean prevalence in Mecklenburg-West Pomerania).

Training for teachers: Teachers received materials on tooth structure and development, epidemiology and definition of caries, information on the aetiology of caries and on strategies for the prevention of caries.

\section{Description of the teaching material on vaccination:}

Background: The teaching material on vaccination tries to increase the vaccination rate and the acceptance for vaccinations. Therefore, the $\mathrm{GeKo}^{\mathrm{KidS}}$ programme supported teachers in giving hints about possible lacks of vaccination referring to the Vaccination-Schedule issued by the STIKO ("Ständige Impfkommission", a committee at the Robert-Koch-Institute, affiliated to the German Government Health Authorities, which recommends vaccinations; Robert Koch-Institut 2009b). The main goal of this teaching material is to increase students' HL by transforming the knowledge that vaccinations can avoid life-threatening diseases such as hepatitis, tetanus, and poliomyelitis into a completion of the vaccination card.

Teaching material: The teaching material for the school subject biology contains worksheets for visualisation of vaccination-related diseases (e.g. mumps, measles, pertussis) and a vaccination schedule. The teaching material for the school subject maths contains worksheets using calculation of percentage to determine the immunisation rate and to compare the class-specific vaccination rate with the vaccination rate of West and East Germany. In order to motivate students competitions were offered to identify the class with the highest vaccination rate.

Training for teachers: The diseases which can be avoided by vaccinations were exemplified. The materials on health education were based on recommendations made by the STIKO.

\section{Description of the teaching material on preventing of starting smoking:}


Background: The material on the prevention of smoking emphasizes four topics: 1. information on teaching principles of the prevention of starting smoking, 2. description of the problem of tobacco-smoking, 3. description of general prevention treatments (1.-3. see „training for teachers“), and 4. information on teaching materials for $5^{\text {th }}$ and $6^{\text {th }}$ grade students (see ,teaching material“").

Teaching material (Bundeszentrale für gesundheitliche Aufklärung 2005; Bundeszentrale für gesundheitliche Aufklärung 2007; Bundeszentrale für gesundheitliche Aufklärung 2009): The teaching material is available in a modular form which lead teachers to plan and conduct their lessons in a flexible way. In grade 5 and 6 the thematic focus is on the examination of the issue "children and smoking - between attempt and temptation" including the following questions: Which needs, wishes and interests do children associate with tobacco-smoking? Which role does tobacco-smoking play in the social life of children? How do children learn about the health-related consequences of tobacco-smoking? How do they evaluate these consequences? In which way can children be motivated to stay non-smoker?

The teaching material also includes practical hints as well as working- and information-sheets, cartoons, role-playscenarios, interview guidelines, tips for planning and realising exhibitions, surveys, events and internet-research.

Furthermore the „Curriculum Training Course Against Smoking“ is also part of the teaching material and focuses on students who already smoke.

Training for teachers: Within the training for teachers principles of the prevention of starting smoking were described and discussed (e.g. the developmental tasks of children and adolescents referring to the area of conflict between person, environment and drug). Therefore a closer look at the beginning of the adolescence lead to the more sophisticated perspective that a sufficient prevention of drug-usage has to be based on a productive examination of the children's developmental tasks and is combined with the following goals: 1. an examination of one's personality, 2. the development of social skills and competences to form, keep and close friendships, 3. an evaluation of typical living conditions referring to potential risks, and 4. the ability to maintain one's position in ,situations of temptation“. The material of the teacher's training also included a presentation of recent epidemiologic results, described the health-related, economic, psychological and pharmacological consequences of tobacco-smoking of the adolescent and the possibilities of structural prevention (e.g. increasing taxation, fight against smuggling, advertising ban, restricting distribution, mass-media campaigns) and behaviour oriented prevention (especially focussed on the promotion of personal, social and professional competence).

\section{Description of the teaching material on prevention of chronic pain:}

Background: This teaching material tries to inform students about the prevalence of pain and existing pain management strategies for children and adolescents. It is based on representative data from the German Health Interview and Examination Survey for Children and Adolescents KiGGS (Ellert et al. 2007) as well as populationbased surveys (Franze et al. 2010b; Fendrich et al. 2007)

Teaching material: The information for students is embedded in a so-called "Pain Quiz" with two teams competing and can be used as an introduction for teaching the topic ,pain in children and adolescents“. It includes questions like "What do you think: how many percent of children aged 3 to 10 years (adolescents aged 11 to 17 years respectively) suffered from pain in the last three month? Who suffers more frequently from pain - boys or girls? What do you 
think is the most frequent pain? How many percent of the children (adolescents respectively) reporting pain visit a doctor (take medicines respectively) because of their pain?

This teaching unit is particularly suitable for the school subjects biology, maths and can also be integrated in the school social work.

Training for teachers: Referring to the studies mentioned above teachers were informed about the prevalence of pain and management strategies of children and adolescents. It was also emphasized why it is important to keep the topic "pain in children and adolescents" in teachers' minds (e.g. the high amount of affected children and adolescents, absence from school, impairments during homework and leisure time activities, a reduced health-related quality of life, an insufficient usage of health services, the threat of a risky use of pain medication, the threat of chronic manifestation of the pain in adulthood and simultaneously a high amount of health-related costs).

\section{Description of the teaching material on nutrition (prevention of overweight and obesity):}

Background: With help of the teaching material on nutrition students should develop awareness for a healthy nutrition-related behaviour. Students should know the components of healthy nutrition, be able to reflect on their own eating habits and develop competence for preparing healthy food.

Teaching material: The teaching material on nutrition consists of five units which are predominant student-orientated and based on student centered learning (Aid-Infodienst/DGE 2007; Aid-Infodienst 2005; Bundeszentrale für gesundheitliche Aufklärung 2004; Aid 2003; Institut Danone e. V 2006). Within the first unit students name the most important nutrients and their body functions and know the related foods. An additional pictorial illustration ("Energy-Balance-Scale") serves to demonstrate the relationship between nutrients and energy supply. Within the second unit students classify their regulary consumed food into different food groups. This unit also includes knowledge of the "food pyramid" and recommendations on healthy food. The third unit offers several learning stations which allow studnets to taste and smell different fruits and vegetables, and to allocate sweets, snacks and beverages to different amounts of sugar and fat content. Within the fourth unit students learn how to arrange a healthy breakfast including aspects of food shopping. The invitation of other classmates to a breakfast and positive experiences while eating jointly is the goal of the fifth unit.

Training for teachers: Referring to overweight and obesity teachers were informed about epidemiological and medically aspects (e.g. definition of overweight and obesity, prevalence rates, associated diseases). The concept of optimized mix of nutrition (Alexy et al. 2008) and the so called children food ("Kinderlebensmittel") were also explained. Furthermore the five teaching units were described in detail.

\section{Description of the teaching material on promoting physical activity:}

Background: The main goal of the teaching material on promoting physical activity is to increase the amount of students who regularly visit sport clubs and exercise in their daily-routine (daily amount of physical activity: 1 hour per day; see Graf et al. 2006). Another goal of this teaching material is to decrease the amount of physical inactivity due to using media such as game consoles etc. (daily amount of physical inactivity: not more than 2 hours per day; see Graf et al. 2006).

Teaching material (Graf et al. 2006): The teaching material consists of three action oriented and student related units. 
The main goal of the first unit with its "fitness-pyramid" is to reflect the students' amount of physical activity, to demonstrate the recommended physical activity per day and to show possible ways to increase physical activity respectively. The second unit serves to try out several active games. The third unit demonstrates the diversity of sports.

Training for teachers: The three teaching units were described in detail - especially the so called "Fitness-Olympics" including the application of the „Dordel-Koch-Test“ (a test for assessing children’s and adolescents` motor skills; see Graf et al. 2006).

\section{Methods}

In order to attain a high participation of the schools the school principals were informed about the research project by an invitation letter, telephone calls and personal visits. Additionally an agreement on participation was handed out to all schools. This agreement was a binding criterion for participation; its aim was to assure a high amount of commitment between schools and principal investigators. Signing this agreement schools committed to use the offered teaching material, to participate in teachers' training and evaluation and to provide resources with respect to time and space. At the beginning of school year 2007/2008 all parents of 5th grade students were informed about the research project, the prevention programme, and aspects of data protection. This included an information letter for parents and information within parent-teacher conferences. In order to increase the response rate parents also received a supporting letter of the Minister of Education, Science and Culture of Mecklenburg-West Pomerania, informing about the importance of the research project and of asking support of the study.

In order to promote the networking of schools during the pilot phase three symposia on health promotion and prevention programmes in Mecklenburg-West Pomerania were organized by members of the research staff of the Institute for Community Medicine, Dept. Epidemiology of Health Care and Community Health) of the University of Greifswald. The symposia were highly frequented by teachers, politicians and scientists as well as school dentists and doctors working for the public health departments of Greifswald and East Pomerania (increase of participating persons from 70 ( $1^{\text {st }}$ symposium) to 140 persons ( $3^{\text {rd }}$ symposium)). Participating schools were also invited in two meetings to exchange experiences, to discuss their efforts and special needs to ensure further support during implementation of the GeKo ${ }^{\mathrm{KidS}}$ programme.

The evaluation of the school-based prevention programme $\mathrm{GeKo}^{\mathrm{KidS}}$ included 5th year classes with students aged 913 years in schools in the region of Greifswald and East Pomerania (longitudinal randomised control group pre-postdesign (RCT)). Data collections took place during the extended school dentist examination at the beginning of school year 2007/2008 and at the beginning of the second half term of school year 2008/2009. The extended school dentist examination consisted of medical examinations (including the measurement of dental health, height, weight and waist circumference) and self-completion questionnaires for students. 
Apart from self-developed items for the measurement of dental health and vaccinations the student questionnaires also consisted of standardized modules (Tagmat et al. 2011, DiFranza 2002) and standardized modules used in the KIGGS-survey (Robert Koch-Institut 2003a; Robert Koch-Institut 2003b; Ravens-Sieberer 2003; Ravens-Sieberer \& Bullinger 1998; Ravens-Sieberer et al. 2005; Roth-Isigkeit et al. 2002). The student questionnaire also consisted of self-developed items for the measurement of different aspects of HL (Schmidt et al., 2010):

- knowledge (e.g. "What teeth do you have to take care for in particular when tooth brushing?", "How can vaccination be administered?"),

- communication (e.g. "Did you talk with your parents (friends respectively) about healthy nutrition?"),

- attitude (e.g. "Health is very important to me.", "I like games in which I have to run a lot."),

- behaviour (e.g. „Do you smoke?”, “How often do you eat fruits a day?”) and

- self-efficacy (e.g. "I can solve most problems if I invest the necessary effort.", "If I am in trouble, I can usually think of a solution.").

Additionally to the students questionnaires the parents were asked to fill in a further questionnaire during teacher parent conferences. The questionnaires were sent by mail to those parents who couldn't attend the conferences. The aim of the questionnaire for parents was especially the estimation of socio-economic status the family was living in. Apart from self-developed items on their children's health and parent's dental health the questionnaire was based on the KIGGS-survey parents instrument (Robert Koch-Institut 2003b).

The questionnaires for teachers were self-developed in order to get information about the acceptance of the training (the teaching material respectively) and about the degree of implementation of the GeKoKidS programme (and other preventive programmes respectively).

The study was authorised by the data protection commissioner of Mecklenburg-West Pomerania, the Ministry of Education, Science and Culture of Mecklenburg-West Pomerania and the Ethics Committee of the University Greifswald. Based on the authorization of the data protection concept and concerning selective response parents were not granted a consent, but a right to refuse the participation. This right of refusal persists as long as data are recorded as a pseudonym. Data are deleted, if parents make use of their right of refusal.

The three trainings for teachers were conducted by members of the research staff of the five involved institutes. The trainings were attended by teachers of the school subjects biology and/or physical education who also coordinated the field of health education of their school. Each of the three trainings lasted about 3 hours (contents of the 1st training: 1. Introduction: Health related status of children and adolescents in Germany, 2. Health literacy, 3. Dental Health; Contents of the 2nd training: 1. Nutrition, 2. Physical (in)activity; Contents of the 3rd training: 1. Prevention of smoking, 2. Vaccinations, 3. Prevention of chronic pain). At the end of each training the teachers were asked to fill out a brief evaluation-questionnaire. The trainings were part of the regular training schedule for the teachers. 
Following the trainings, in the schools of the intervention group the teachers could use the materials in regular lectures in the subjects biology, physical education and maths and in the framework of special project days focusing on health education. The implementation lasted from October/November 2007 to January/February 2009. In order to further promote the implementation and to discuss the need for support in April and September 2008 two meetings to exchange experiences, to discuss their efforts and special needs to ensure further support during implementation of the $\mathrm{GeKo}^{\mathrm{KidS}}$ programme were conducted. Within these meetings the teachers received information on current results of the evaluation (e.g. school-specific prevalence rates on caries, overweight and obesity) and recommendations concerning further activities of the schools. To support preventive activities a special competition was arranged (class with the highest amount of dental health and class with the highest vaccination rate at second measure time).

\section{Results}

In Greifswald/East Pomerania 19 of 22 schools with 5th year classes participated in GeKo ${ }^{\text {KidS }}$ (response: 86.3\%; the reason for non-response was lack of interest $(13,7 \%)$. Out of 914 students in the participating schools 882 children (96.4\%) took part in the school dentist examination (reasons for non-response: illness $(3,2 \%)$, emigration $(0,2 \%)$. 863 children (94.4\%) participated in the extended school dentist examination (reasons for non-response: illness $(3,1 \%)$, refusal $(2,1 \%)$, emigration $(0,2 \%) .852$ children $(93.2 \%)$ took part in the survey of students (reasons for nonresponse: illness $(4,2 \%)$, refusal $(2,1 \%)$, emigration $(0,3 \%)$. In the parental survey 721 parents participated (response: $78.8 \%$; reasons for non-response were: lack of interest (18.9\%), refusal (1.7\%), emigration (0.3\%) and moving house after first test interval $(0.1 \%))$.

Within the three offered trainings, the participating teachers should evaluate the training concept and the GeKo ${ }^{\mathrm{KidS}}$ programme referring to its suitability for 5 th/6th grade students. Altogether a high amount of acceptance referring to the teachers' training and the appropriateness of the $\mathrm{GeKo}^{\mathrm{KidS}}$ programme can be reported (see Tab. 1 and 2).

Tab. 1: Evaluation of the teachers' training: Overall rating $(n=22)$

\begin{tabular}{|l|c|}
\hline Training contents & Mean (N) \\
\hline Introduction: Health related status of children and adolescents in Germany & $1.60(22)$ \\
\hline Health literacy & $2.00(22)$ \\
\hline Dental Health & $1.26(22)$ \\
\hline Nutrition & $1.50(18)$ \\
\hline Physical (in)activity & $1.58(18)$ \\
\hline Prevention of smoking & $2.00(19)$ \\
\hline Vaccinations & $1.76(19)$ \\
\hline Prevention of chronic pain & $2.07(19)$ \\
\hline school grades: $1=$ very good, $6=$ insufficient & \\
\hline
\end{tabular}

Tab. 2: Evaluation of the appropriateness of the $\mathrm{GeKo}^{\mathrm{KidS}}$ programme for grade $5 / 6(\mathrm{n}=22)$ 


\begin{tabular}{|c|c|c|c|c|c|}
\hline \multirow{3}{*}{ Topic } & \multicolumn{5}{|c|}{ Using the $\mathrm{GeKo}^{\mathrm{KidS}}$ materials in grade $5 / 6$ is... } \\
\hline & \multicolumn{2}{|c|}{$\begin{array}{c}\text {...too difficult } \\
\mathrm{n}(\%)\end{array}$} & \multicolumn{2}{|c|}{$\begin{array}{c}\text {...appropriate } \\
\text { n }(\%)\end{array}$} & \multirow{2}{*}{$\begin{array}{c}\text {...too easy } \\
\mathrm{n}(\%) \\
\text { grade } \mathbf{5 / 6}\end{array}$} \\
\hline & grade 5 & grade 6 & grade 5 & grade 6 & \\
\hline Dental health & $\begin{array}{c}3 \\
(20)\end{array}$ & $\begin{array}{c}1 \\
(6.67)\end{array}$ & $\begin{array}{c}12 \\
(80)\end{array}$ & $\begin{array}{c}14 \\
(93.33)\end{array}$ & - \\
\hline Nutrition & - & - & $\begin{array}{c}12 \\
(100)\end{array}$ & $\begin{array}{c}10 \\
(100)\end{array}$ & - \\
\hline $\begin{array}{l}\text { Physical } \\
\text { (in)activity }\end{array}$ & - & - & $\begin{array}{c}11 \\
(100)\end{array}$ & $\begin{array}{c}9 \\
(100)\end{array}$ & - \\
\hline $\begin{array}{l}\text { Prevention of } \\
\text { smoking }\end{array}$ & - & - & $\begin{array}{c}13 \\
(100)\end{array}$ & $\begin{array}{c}13 \\
(100)\end{array}$ & - \\
\hline Vaccination & $\begin{array}{c}3 \\
(25)\end{array}$ & $\begin{array}{c}2 \\
(16.67)\end{array}$ & $\begin{array}{c}9 \\
(75)\end{array}$ & $\begin{array}{c}10 \\
(83.33)\end{array}$ & - \\
\hline $\begin{array}{l}\text { Prevention of } \\
\text { chronic pain }\end{array}$ & $\begin{array}{c}3 \\
(25)\end{array}$ & $\begin{array}{c}3 \\
(25)\end{array}$ & $\begin{array}{c}9 \\
(75)\end{array}$ & $\begin{array}{c}9 \\
(75)\end{array}$ & - \\
\hline
\end{tabular}

As a result of the first implementation meeting with the teachers of the intervention schools the participating teachers communicated that the $\mathrm{GeKo}^{\mathrm{KidS}}$ programme was predominantly implemented within health days and was integrated within the school mission statement was not yet implemented within classes. Within the second meeting of minds the teachers reported that the $\mathrm{GeKo}^{\mathrm{KidS}}$ programme had been further implemented within classes.

\section{Discussion}

A high response rate is a crucial condition for the validity and generalizability of results from an epidemiological study (Drivsholm et al. 2006). Important factors for a high response are an accompanying multimodal public relation-strategy, the use of ,incentives“, the design and dispatch of study information material as well as questionnaires, the method of establishing contact before sending the questionnaires, and the subject's interest in the object of research (Hoffmann et al. 2004; Latza et al. 2004).

Referring to the low rate of refusal and the teachers' feedback, the GeKo ${ }^{\text {KidS }}$ programme and its evaluation in the framework of an extended school dentist examination seems to be well accepted. This is also important due to the results of the KiGGS-survey (Robert Koch-Institut 2008) which also demonstrates the necessity of early interventions.

Possible reasons for the acceptance of the programme and of the evaluation could be the method of establishing contact before sending the questionnaires and the parent's right to refuse the participation of their child instead of giving an active confirmation. Due to this high response rate the data base enables comprehensive conclusions on the health-related state of students in Greifswald/East Pomerania and also enables comparisons with the results of the KIGSS survey. 
According to the teacher's evaluation the teaching material is appropriate for students in grade 5/6. There is no need for teachers to change the material. The material is easy to integrate in the regular curriculum of the school subject biology in grade 5 which offers a good opportunity to implement such a programme.

Health-promoting and prevention-orientated activities in schools are a long-lasting task (Franze et al. 2007). This can be demonstrated referring to the feedback of the teachers within the two meetings to exchange experiences: an implementation of the $\mathrm{GeKo}^{\mathrm{KidS}}$ programme in the classes was conducted after one year. Due to the general limitation of funding periods this circumstance is a problematic one for the evaluation of intervention studies in this kind of setting and should be considered by subsidy practices (e.g. by the Federal Ministry of Education and Research Germany).

In the framework of a Federal Press Conference held in April 2010 the GeKoKidS programme was presented by the head of project (Splieth C \& Hoffmann W), the project coordinator (Franze M) and the Minister of Education, Science and Culture of Mecklenburg-West Pomerania. In terms of disseminating the GeKoKidS programme and in his capacity as the chairman of the Ministers of Education ("Kultusministerkonferenz") the Minister of Education, Science and Culture of Mecklenburg-West Pomerania also informed the other state education ministers about the programm and its accessability (Franze, Hoffmann, Splieth 2010a).

\section{The authors declare that they have no conflict of interest.}

\section{Acknowledgment}

The study was funded by the Federal Ministry of Education and Research Germany (grant No. 01EL0610). 


\section{References}

Aid-Infodienst/DGE (2007) OptimiX: Empfehlung für die Ernährung von Kindern und Jugendlichen. aid-infodienst. http://www.aid.de. Accessed 29 March 2011

Aid-Infodienst (2005) Die aid-Ernährungspyramide - Richtig essen lehren und lernen aid-infodienst. http://www.aid.de. Accessed 29 March 2011

Aid (2003) Esspedition Schule - Materialien zur Ernährung Klasse 1 - 6. Ministerium für Ernährung und Ländlichen Raum (Hrsg.), Baden-Württemberg

Alexy U, Clausen K, Kersting M (2008) Die Ernährung gesunder Kinder und Jugendlicher nach dem Konzept der optimierten Mischkost. Ernährungsumschau 3 (08): 168-174

Baker DW, Parker RM, Williams MV, Clark WS, Nurss J (1997) The relationship of patient reading ability to selfreported health and use of health services. Am J Public Health 87(6):1027-1030

Bundeszentrale für gesundheitliche Aufklärung (2009) „Auf dem Weg zur rauchfreien Schule“. Köln: Bundeszentrale für gesundheitliche Aufklärung

Bundeszentrale für gesundheitliche Aufklärung (2005) „Rauchen“. Köln: Bundeszentrale für gesundheitliche Aufklärung

Bundeszentrale für gesundheitliche Aufklärung (2007) Curriculum "Anti-Rauchkurs". Köln: Bundeszentrale für gesundheitliche Aufklärung

Bundeszentrale für gesundheitliche Aufklärung (2004) Ernährung und Gesundheit - Materialien für 5.-10. Klassen. Köln: Bundeszentrale für gesundheitliche Aufklärung

Conwell LS, O`Callaghan MJ, Andersen MJ, Bor W, Najman JM, Williams GM (2003) Early adolescent smoking and a web of personal and social disadvantage. J.Paediatr.Child Health 39(8):580-585

DiFranza JR, Savageau JA, Rigotti NA, Fletcher K, Ockene JK, McNeill AD, Coleman M, Wood C. (2002) Development of symptoms of tobacco dependence in youths: 30 month follow-up from the DANDY study. Tobacco Control 11: 228-235

Drivsholm T, Eplov LF, Davidsen M, Jørgensen T, Ibsen H, Hollnagel H, Borch-Johnsen K (2006) Representativeness in population-based studies: a detailed description of non-response in a Danish cohort study. Scand J Public Health 34(6):623-31

Ellert U, Neuhauser H, Roth-Isigkeit A (2007) Schmerzen bei Kindern und Jugendlichen in Deutschland: Prävalenz und Inanspruchnahme medizinischer Leistungen. Ergebnisse des Kinder- und Jugendgesundheitssurveys (KiGGS). Gesundheitswesen 50:711-717

Fendrich K, Vennemann M, Pfaffenrath V, Evers S, May A, Berger K, Hoffmann, W (2007) Headache prevalence among adolescents - the German DMKG headache study. Cephalalgia 27:347-354 
Franze M, Hoffmann W, Splieth C (2010a) GeKoKidS - Unterrichtsmodule und Monitoringsystem zur Förderung gesundheitsbezogener Kompetenzen für Klassenstufe 5/6. Greifswald: Ernst-Moritz-Arndt-Universität Greifswald; ISBN-Nr. 978-3-86006-348-4. http://www.bildung-mv.de/export/sites/lisa/de/startseitennachrichten/download/ GEKOKIDS-UNTERRICHTSMODULE.pdf. Accessed 29 March 2011]

Franze M, Fendrich K, Schmidt C O, Splieth C, Hoffmann W (2010b) Schmerzen und Schmerzmanagement bei Kindern in Greifswald und Ostvorpommern: Vergleich mit den Ergebnissen des Kinder- und Jugendgesundheitssurveys (KiGGS). Das Gesundheitswesen; DOI 10.1055/s-0029-1242785

Franze M, Meierjürgen R, Abeling I, Rottländer M, Gerdon R, Paulus P (2007) MindMatters - Ein Programm zur Förderung der psychischen Gesundheit in der Sekundarstufe I. Deutschsprachige Adaptation und Ergebnisse des Modellversuchs. Prävention und Gesundheitsförderung 4:221-227

Gazmararian JA, Kripalani S, Miller MJ, Echt KV, Ren J, Rask K (2006) Factors associated with medication refill adherence in cardiovascular-related diseases: a focus on health literacy. J Gen Intern Med 21(12):1215-1221

Goodman E (1999) The role of socioeconomic status gradients in explaining differences in US adolescents' health. Am J Public Health 89(10):1522-1528

Graf C, Dordel S, Koch B, Predel H-G (2006) Bewegungsmangel und Übergewicht bei Kindern und Jugendlichen. Deutsche Zeitschrift für Sportmedizin 57(9):220-225

Hawthorne G. Preteenage drug use in Australia: the key predictors and school-based drug education. Journal of adolescent health 1997; 20(5):384-395

Hoffmann W, Terschüren C, Holle R, Kamtsiuris P, Bergmann M, Kroke A, Sauer S, Stang A, Latza U. (für die gemeinsame Arbeitsgruppe "Epidemiologische Methoden" der Deutschen Arbeitsgemeinschaft Epidemiologie (DAE), der Deutschen Gesellschaft für Sozialmedizin und Prävention (DGSMP) und der Deutschen Gesellschaft für Medizinische Statistik, Biometrie und Epidemiologie (gmds)) (2004) Zum Problem der Response in epidemiologischen Studien (Teil 2). Das Gesundheitswesen 66:482-491

Institut Danone e. V (2006) Ringordner: Ernährung für Kinder - Unterrichtsmaterialien für Grundschulen.

Jaescke, R. (2006) Lust auf Bewegung - 111 Bewegungsspiele für Schule, Alltag und Therapie, Stamsried: CARELINE Verlag GmbH

Kay E, Locker D (1998) A systematic review of the effectiveness of health promotion aimed at improving oral health. Community Dent Health 15:132-44

Latza U, Stang A, Bergmann M, Kroke A, Sauer S, Holle R, Kamtsiuris P, Terschüren C, Hoffmann W. (für die gemeinsame Arbeitsgruppe "Epidemiologische Methoden" der Deutschen Arbeitsgemeinschaft Epidemiologie (DAE), der Deutschen Gesellschaft für Sozialmedizin und Prävention (DGSMP) und der Deutschen Gesellschaft für Medizinische Statistik, Biometrie und Epidemiologie (gmds)) (2004) Zum Problem der Response in epidemiologischen Studien (Teil 1). Das Gesundheitswesen 66:326-336 
Mancuso CA, Rincon M (2006) Impact of health literacy on longitudinal asthma outcomes. Journal of General Internal Medicine 21(8):813-817

Nutbeam D (2000) Health literacy as a public health goal: a challenge for contemporary health education and communication strategies into the 21st century. Health Promotion International 15: 259-267

Ravens-Sieberer U (2003) Der Kindl-R-Fragebogen zur Erfassung der gesundheitsbezogenen Lebensqualität bei Kindern und Jugendlichen - Revidierte Form. In: Schumacher JKA, Brähler E (Ed) Diagnostische Verfahren zu Lebensqualität und Wohlbefinden. Hogrefe, Göttingen, pp 184-188.

Ravens-Sieberer U, Bullinger M (1998) Assessing health related quality of life in chronically ill children with the German KINDL: first psychometric and content analytical results. Qual Life Res 7: 399-407

Ravens-Sieberer U, Gosch A, Rajmil L, Erhart M, Bruil J, Duer W, Auquier P, Power M, Abel T, Czemy L, Mazur J, Czimbalmos A, Tountas Y, Hagquist C, Kilroe J and the European KIDSCREEN Group (2005) KIDSCREEN-52 quality-of-life measure for children and adolescents. Expert Review of Pharmacoeconomics \& Outcomes Research $5(3): 353-364$

Robert Koch-Institut (2003a) Studie zur Gesundheit von Kindern und Jugendlichen in Deutschland. Kinder. 11-13 . Berlin: Robert Koch-Institut

Robert Koch-Institut (2003b) Studie zur Gesundheit von Kindern und Jugendlichen in Deutschland. Eltern. 11-13 . Berlin: Robert Koch-Institut

Robert Koch-Institut (2008) Lebensphasenspezifische Gesundheit von Kindern und Jugendlichen in Deutschland. Ergebnisse des Nationalen Kinder- und Jugendgesundheitssurveys (KiGGS). Bericht für den Sachverständigenrat zur Begutachtung der Entwicklung im Gesundheitswesen. Berlin: Robert Koch-Institut. http://www.kiggs.de/experten/downloads/dokumente/KiGGS_SVR\%5B1\%5D.pdf. Accessed 29 March 2011

Robert Koch-Institut (2009a). Krankheitskosten. Gesundheitsberichterstattung des Bundes 48. Berlin: Robert KochInstitut

Robert Koch-Institut (2009b) Impfkalender. Epidemiologisches Bulletin 30:280

Roth-Isigkeit A, Ellert U, Kurth BM (2002) Die Erfassung von Schmerz in einem Kinder- und Jugendgesundheitssurvey. Gesundheitswesen 2002;64 Suppl 1:S125-S129

Seiberl J, Plachta-Danielzik S, Franze M, Hoffmann W, Splieth C, Müller M J (2009) Das Schulfrühstück von 9- bis 13-jährigen Kindern - Erfahrungen von GeKoKidS (Gesundheitskompetenz bei Kindern in der Schule). Ernährungs Umschau. 56:498-505

Sharif I, Blank AE (2010) Relationship between child health literacy and body mass index in overweight children. Patient Education and Counseling 79(1):43-8

Schiffner, U Bauch J (1986) Das Kindergartenbetreuungsprogramm ist in erster Linie bei der Mittelschicht effektiv. Zahnärztl Mitt 76:938-41 
Schillinger D, Grumbach K, Piette J (2002) Associations of Health Literacy with Diabetes Outcomes. American Medical Association 288(4):475-482

Schmidt C O, Fahland R A, Franze M, Splieth C, Plachta-Danielzik S, Thyrian R, Hoffmann W, Kohlmann T (2010) Health related behaviour, knowledge, attitudes, communication, and social status in German school children. Health Education Research 25(4):542-551

Splieth CH, Steffen H, Welk A, Schwahn C (2005) Responder and nonresponder analysis for a caries prevention program. Caries Res. 39(4):269-72

Splieth CH, Nourallah AW, König KG (2004) Caries prevention programs for groups: out of fashion or up to date? Clin Oral Investig 8(1):6-10

Tagmat, Wolff, John, Thyrian (2011). Development and psychometric properties of a short situational urge to smoke scale (SUS) for smoking adolescents. Substance use \& misuse. doi:10.3109/10826084.2010.540288

Trummler A, Weiss V (2000) DMFT scores in 12 year old school children in the city of St. Gallen. Oralprophylaxe 22:206-208

Von Wagner C, Knight K, Steptoe A, Wardle J (2007) Functional health literacy and health-promoting behaviour in a national sample of British adults. J Epidemiol Community Health 61:1086-1090

Wolf MS, Gazmarian JA, Baker DW (1946-1952) Health literacy and functional health status among older adults. Arch.Intern.Med 165 (17)

Zimmer S, Robke FJ, Roulet JF (1999) Caries prevention with fluoride varnish in a socially deprived community. Community Dent Oral Epidemiol 27:103-8 